\title{
Induction Heating for Variably Sized Ferrous and Non-Ferrous Materials through Load Modulation
}

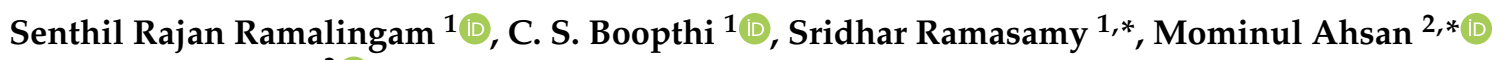 \\ and Julfikar Haider ${ }^{3}$ (D) \\ 1 Department of Electrical and Electronics Engineering, SRM Institute of Science and Technology, \\ Chennai 603203, India; senthilrajanpr@gmail.com (S.R.R.); boopathc1@srmist.edu.in (C.S.B.) \\ 2 Department of Computer Science, University of York, Deramore Lane, York YO10 5GH, UK \\ 3 Department of Engineering, Manchester Metropolitan University, John Dalton Building, Chester Street, \\ Manchester M1 5GD, UK; j.haider@mmu.ac.uk \\ * Correspondence: sridharr@srmist.edu.in (S.R.); md.ahsan2@mail.dcu.ie (M.A.)
}

check for updates

Citation: Ramalingam, S.R.; Boopthi, C.S.; Ramasamy, S.; Ahsan, M.; Haider, J. Induction Heating for Variably Sized Ferrous and Non-Ferrous Materials through Load Modulation. Energies 2021, 14, 8354. https://doi.org/10.3390/en14248354

Academic Editor: Byoung Kuk Lee

Received: 25 October 2021

Accepted: 7 December 2021

Published: 11 December 2021

Publisher's Note: MDPI stays neutral with regard to jurisdictional claims in published maps and institutional affiliations.

Copyright: (c) 2021 by the authors. Licensee MDPI, Basel, Switzerland. This article is an open access article distributed under the terms and conditions of the Creative Commons Attribution (CC BY) license (https:// creativecommons.org/licenses/by/ $4.0 /)$.

\begin{abstract}
Induction heating $(\mathrm{IH})$ is a process of heating the electrically conducting materials especially ferromagnetic materials with the help of electromagnetic induction through generating heat in an object by eddy currents. A well-entrenched way of $\mathrm{IH}$ is to design a heating system pertaining to the usage of ferromagnetic materials such as stainless steel, iron, etc., which restricts the end user's choice of using utensils made of ferromagnetic only. This research article proposes a new scheme of induction heating that is equally effective for heating ferromagnetic and non-ferromagnetic materials such as aluminium and copper. This is achieved by having a competent IH system that embodies a series resonant inverter and controller where a competent flexible load modulation (FLM) is deployed. FLM facilitates change in operating frequency in accordance with the type of material chosen for heating. The recent attempts by researchers on all metal IH have not addressed much on the variable shapes and sizes of the material, whereas this research attempts to address that issue as well. The proposed induction heating system is verified for a $2 \mathrm{~kW}$ system and is compatible with both industrial and domestic applications.
\end{abstract}

Keywords: induction heating; load flexible modulation; series resonant inverter; non-ferromagnetic materials

\section{Introduction}

Traditionally, heat energy is produced by burning combustible substances, which results in energy wastage and environmental deterioration. Over the years, these drawbacks forced researchers to invent new heating methodologies. In the recent past, induction heating $(\mathrm{IH})$ methods based on magnetic coupling have evolved tremendously because of their innate advantages such as no leftovers, cleanliness, safety, and high efficiency [1-3]. In induction hardening, aside from the reduced processing time, cost reduction and less decarburisation are also added advantages [4]. However, the method also has drawbacks such as a shorter austenitisation period, which is insufficient to provide a uniform carbon distribution, resulting in variances in a martensitic block size that depends on the local carbon concentration. As a result, the tensile strength of the steel is lower than that of the conventionally heat-treated steel [5]. In the metal melting process for diecasting, a DC induction heater with high-temperature superconductor (HTS) coils can save both energy and time [6]. With the advent of power electronic switches and power converter circuitries, the IH phenomena gained the attention of researchers. The IH system essentially comprises two important components-namely, the working coil and work bit (load). Traditionally, $\mathrm{IH}$ is a combined recipe of electromagnetic induction and joule heating. IH is a non-contact process of heating electrically conductive metal by generating eddy currents in the metal using the principle of electromagnetic induction. Thus, the eddy current, based on the joule 
heating principle, flows against the resistivity of the metal producing heat in the metal. The conventional topology used in IH consists of an AC to DC converter and the load. However, this system can only be used for ferromagnetic materials of high resistance with low skin depth and high permeability, and therefore, the use of this technique on different other metals with low resistance in different applications is challenging [7-11].

Many research initiatives and techniques have been proposed to heat non-ferromagnetic materials [12-16] and non-metallic materials [17] using IH. The prime inference from this body of research is that non-ferromagnetic material has much lower resistance than ferromagnetic materials, which results in drawing more current from the inverter, which requires higher-rated components, increasing the switching losses and costs of the system. The resistance of non-ferromagnetic materials has been increased by increasing the switching frequency, which also causes a decrease in the skin depth. However, due to an increase in the switching frequency, high switching losses are inevitable. The idea of increasing the resistance of non-ferromagnetic materials is implemented by the high turns ratio of the $\mathrm{IH}$ coil, which increases conduction losses in the system, making the system unstable. The resistance in the circuit causes some damping in the series RLC circuit. It determines whether or not the circuit will naturally resonate in the absence of a driving source. Circuits that will resonate in this manner are considered to be underdamped, while those that will not are considered to be overdamped. There is also a condition known as critical damping, which is the smallest amount of damping that can be applied without causing oscillation [18].

Many researchers have put forth their research contribution in IH either through new topologies of converter or through control algorithms [19-28]. Research by Saha and Kim suggested a series inverter using third-harmonic modulation to increase the resistance of ferromagnetic materials [29]. Here, in this method, the operating frequency was three times higher than that of the switching frequency. On the other hand, the input voltage was three times lower than the traditional pulse frequency modulation. Therefore, to deliver the rated power with a low input voltage, a high current was drawn from the system; in turn, the system capacity increased, and the choice of switches became a cumbersome procedure. To overcome this issue, a power factor correction circuit was combined with the system, which increased the input voltage and solved the low input voltage problem. However, large, passive components contributed to the poor cost effectiveness of the IH system and also unnecessarily increased additional passive components in the topology [30].

In a research study, Park and Jung demonstrated a technique of heating both ferromagnetic and non-ferromagnetic materials [12]. Inspired by their research, the authors of this research paper carried the research forward by proposing schemes to use a simple control technique for heating all metals with different shapes and sizes. Figure 1 shows two different systems for heating different pan shapes and sizes.

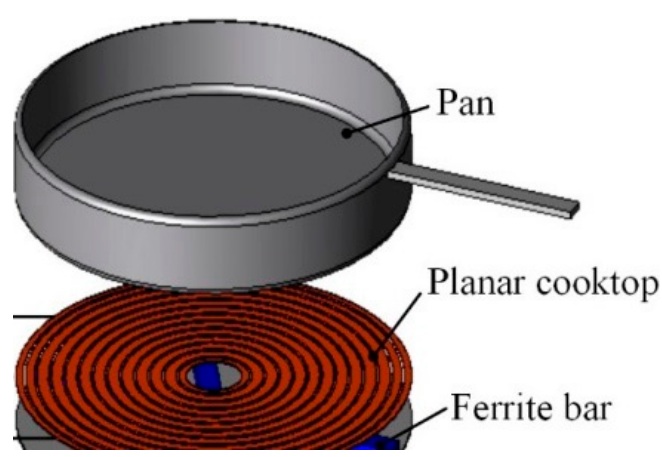

(a)

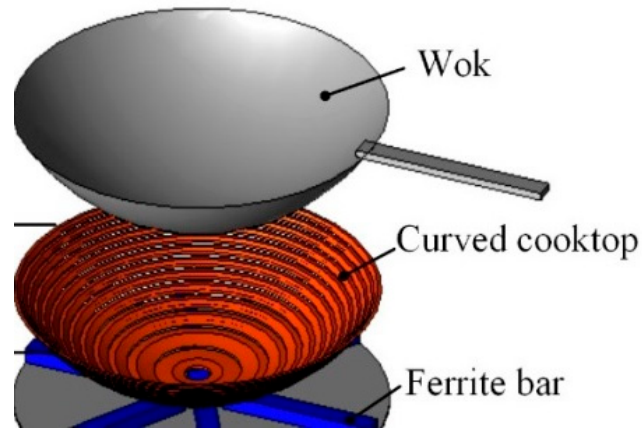

(b)

Figure 1. Heating metal of different shapes and sizes: (a) planar cooktop and (b) curved cooktop. 
Flexible load modulation (FLM) was achieved with the help of a controller in this system. Two switches were deployed in this prototype for two different modes, which had different switching and resonant frequencies for each mode. The inductor in the resonant tank circuit was kept constant, whereas two different capacitors were available for each mode. Depending on the metal used, the mode was selected with the help of switches available. When any load was removed, the system would come to its initial condition. From the literature survey, it is inferred that there is a need to simplify the system, along with reducing switching and conduction losses without using additional high-rated passive components and to increase the system efficiency.

In this research study, the FLM method for heating different metals by a series resonance circuit is proposed. The control algorithm thus devises the operational modes, minimising the magnitude of resonant current by increasing the resistance of the metal, as shown in Figure 2. This topology does not require any power factor correction circuit and hence making it cost effective and with improved power density. Furthermore, since the switching frequency is different and less than that of the operating frequency, a very small switching loss is incurred. The turn ratio of the IH coil is kept low to achieve very low conduction losses. This paper is organised as follows: Section 2 presents the system description and proposed methodology. The results are discussed in Section 3, and the concluding remarks are given in Section 4.

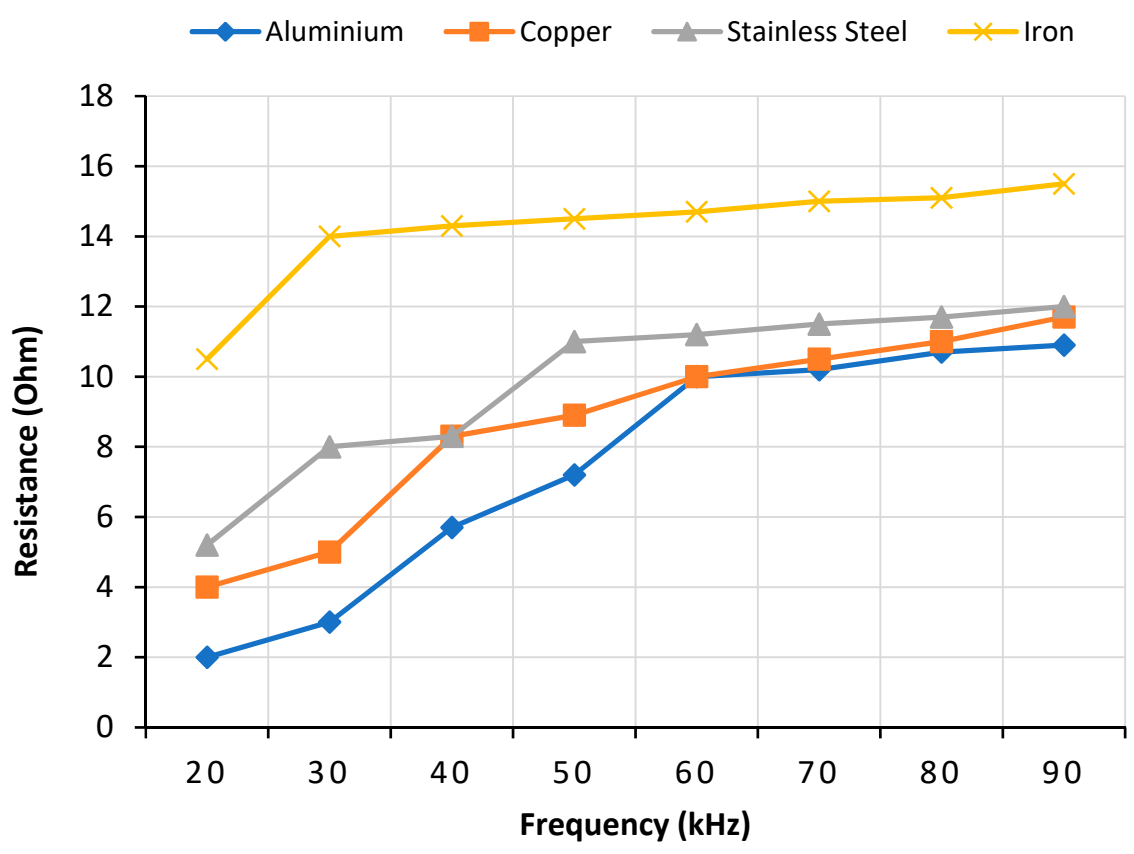

Figure 2. Frequency vs. resistance of different ferromagnetic and non-ferromagnetic materials (data taken from [31,32]).

\section{Design of Induction Heating System}

\subsection{System Description}

In this proposed induction heating system, input was received by $220 \mathrm{~V}$ DC bus from three different sources-namely, $220 \mathrm{~V}$ AC supply (grid), PV array, and battery. For this system, the $220 \mathrm{~V}$ AC supply taken from the grid could be reduced to the desired voltage with the help of an autotransformer and the controlled rectifier. The output of the PV array was fed to the DC-DC converter in order to convert it into the required voltage and transfer it to the $220 \mathrm{~V}$ DC bus. When there was no PV power, the battery was discharged to the load, whereas the battery was charged when the PV power was available. This is the function of the nanogrid, which automatically controlled the charging and discharging of the battery based on the availability of other sources and the load. A half-bridge resonant converter was connected to the DC bus. This converter was used to change the operating 
frequency of the IH coil. Several combinations of inductor and capacitor were controlled by switches (S3 and S4) to change the operating frequency. To control the switches in the resonant tank and to give PWM pulses to MOSFET (S1 and S2), a controller was employed. This controller changed the pulses generated and the switches in the resonant tank as per the mode selected. The block diagram of the proposed system is shown in Figure 3. Here, the induction heater was powered by the nanogrid, which was used to reduce the electricity bill and also the burden on the grid. The nanogrid was employed as a valuable addition to this study because it is an emerging technology that has considerable benefits for both consumers and distributors.

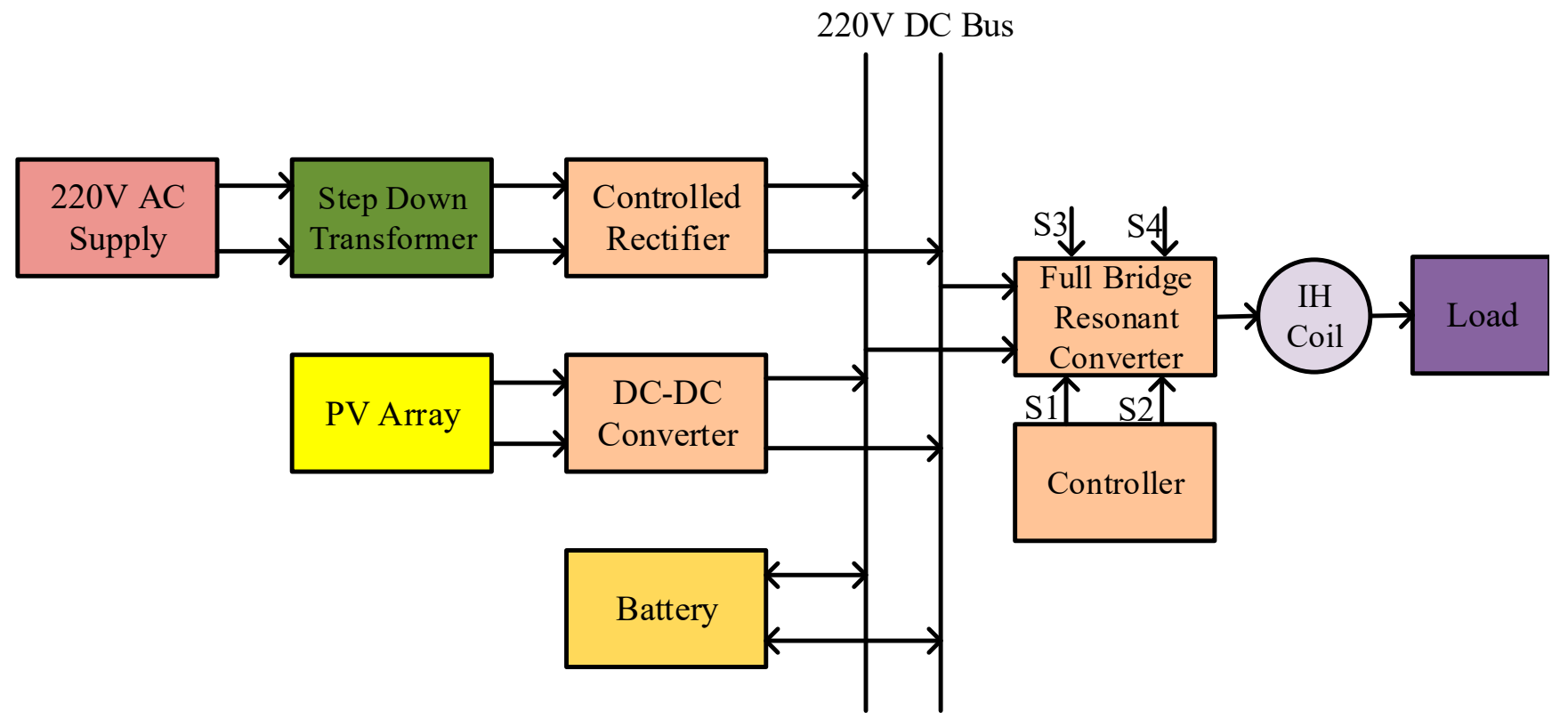

Figure 3. Block diagram of the proposed induction heating system.

\subsection{System Topology}

In this system, flexible load modulation (FLM) was proposed to heat both ferrous and non-ferrous metals with the help of various types of operations. FLM was achieved with the help of a controller in this system. Two switches were deployed in this prototype system for two different operational modes (ferrous and non-ferrous), which had different PWM pulses. The inductor in the resonant tank circuit was kept constant, whereas two different capacitors were available for each mode. Depending on the metal to be heated, the mode was selected by means of the resistance of the metal with the help of the switches available.

Figure 4 presents circuit diagrams for heating ferrous and non-ferrous metals. The circuit diagram comprised a DC voltage source and a half-bridge resonant converter. This converter was made up of two MOSFET switches-S1 and S2. The output of this converter was fed into the IH coil through various combinations of inductors, capacitors, and switches. The switches S3 and S4 played key roles in the mode selection. For example, if switch S3 turned on the receiving controller, the command to operate the series resonant inverter in mode 1, hence the PWM required for mode 1, was given to the MOSFETs, and the capacitor required for this mode was selected with the help of relay circuit, coupled with the controller. If the load changed, then according to the load, the mode of operation was selected based on the resistance of the metal that required heating. 


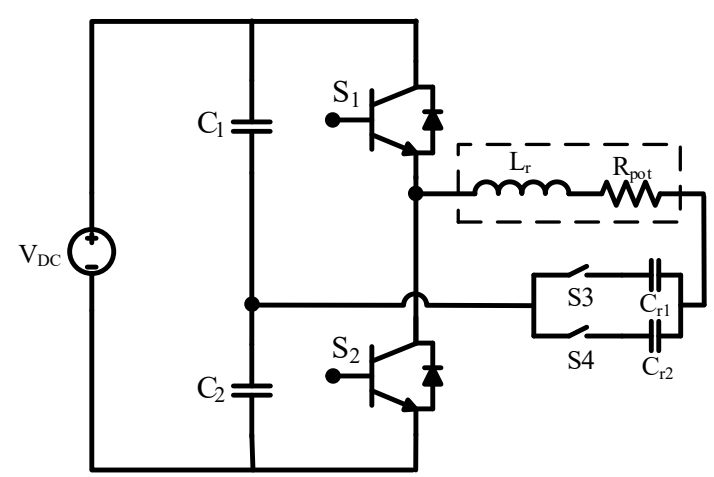

Figure 4. Proposed circuit diagram for ferrous and non-ferrous heating modes.

\subsection{Modes of Operation}

2.3.1. Ferrous Heating Mode

In the ferrous heating mode, as shown in Figure 5, the equivalent voltage for the series resonant inverter was half as that of the input voltage $(220 \mathrm{~V})$ that was transferred to the load. Figure 6 shows the PWM pulses required for the MOSFET switches.

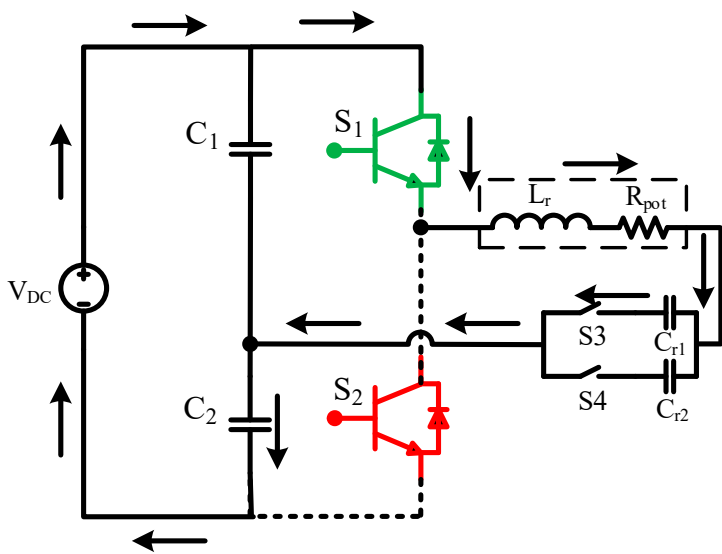

(a)

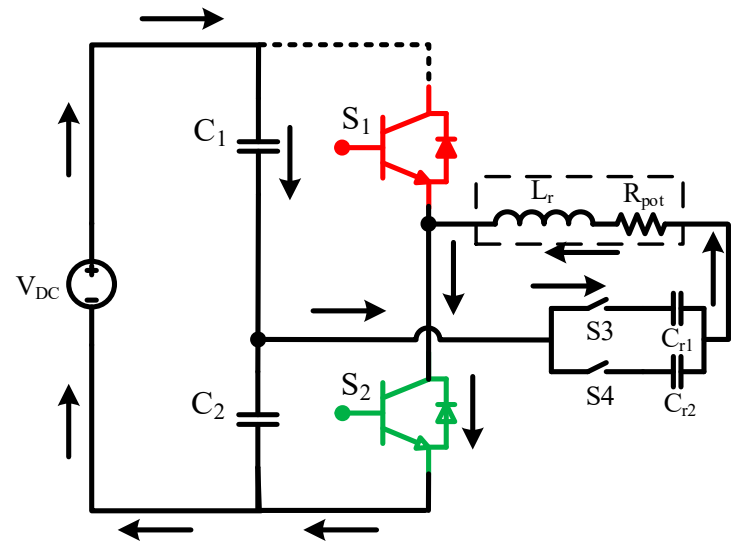

(b)

Figure 5. Circuit diagrams for ferrous heating mode: (a) S1 in ON state; (b) S2 in ON state.

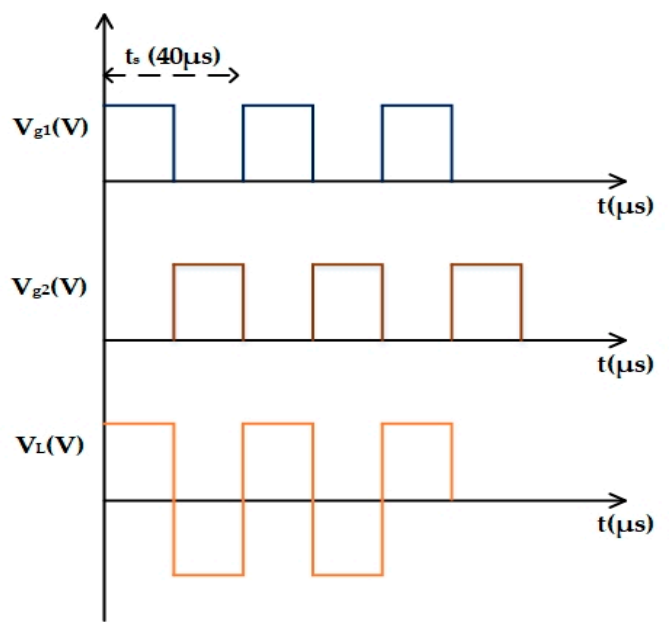

Figure 6. Theoretical voltage waveforms for ferrous heating mode.

Based on the pulses, it was evident that the switches S1 and S2 worked alternatively. When the switch S1 was switched on, the power from the source was transferred to the coil through S1, $L_{r}, R_{\text {pot }}, C_{r 1}$, and S3. After that, switch S1 was turned off, and S2 was turned 
on; the power flow was in the direction through S3, $C_{r 1}, R_{p o t}, L_{r}$, and S2. The maximum power supplied to the load at resonance frequency is given by Equation (1).

$$
P_{f}=\frac{V_{i n}^{2}}{4 R_{p o t}}
$$

where $P_{f}$ is the maximum power in the ferrous heating mode, $V_{\text {in }}$ is the input voltage to the inverter, and $R_{\text {pot }}$ is the resistance of the metal at the load. The operating frequency of the series resonant inverter in this mode remained the same as the switching frequency. Equation (2) provides the resonance frequency for an LC circuit.

$$
F_{S}=\frac{1}{2 \pi \sqrt{L r C r}}
$$

where $F_{S}$ is the resonance frequency, $L_{r}$ is the coil inductance, and $C_{r}$ is the resonant capacitance. The ferrous heating mode can be used to heat ferromagnetic materials such as iron, stainless steel, etc. Equation (2) can also be rewritten by including the $Q$ factor as

$$
F_{s}=\frac{R_{p o t} Q}{2 \pi L_{r}}
$$

where $Q$ is the quality factor which is the measure of the quality of the resonant circuit and it can be expressed by Equation (4).

$$
Q=\frac{1}{R_{p o t}} \sqrt{\frac{L_{r}}{C_{r}}}
$$

Equations (2) and (3) hold true for an ideal lossless circuit. However, there are losses in this case that represent both the reduced load and active resistance of the winding. Therefore, it can be written as Equation (5).

$$
F_{s}=\frac{1}{2 \pi} \sqrt{2 \pi F_{0}^{2}-\alpha^{2}}
$$

where $F_{0}$ is the natural frequency without any losses, and $\alpha$ is the damping attenuation in nepers per second, which can be expressed as Equation (6).

$$
\alpha=\frac{R_{p o t}}{2 L_{r}}
$$

\subsubsection{Non-Ferrous Heating Mode}

In the non-ferrous heating mode, shown in Figure 7, the operating frequency of the inverter was twice the switching frequency. The PWM pulses are listed in Figure 8.

With these pulses, the energy was transferred to the load and pulses when the switch $\mathrm{S} 1$ was $\mathrm{ON}$ or $\mathrm{S} 2$ was ON. For the first condition, when $\mathrm{S} 1$ was in the ON state, the energy transfer was through S1, $L_{r}, R_{p o t}, C_{r 2}$, and S4, and for when S2 was in the ON state, the energy flow was in the direction through $S 4, C_{r 2}, R_{p o t}, L_{r}$, and $\mathrm{S} 2$. The maximum power available in this mode is given by Equation (7).

$$
P_{n f}=\frac{V_{i n}{ }^{2}}{4 R_{p o t}}
$$

where $P_{n f}$ is the maximum power in the non-ferrous heating mode, $V_{i n}$ is the input voltage to the inverter, and $R_{p o t}$ is the resistance of the metal at the load. This mode of operation is generally used to heat non-ferromagnetic materials such as aluminium; since the resistance of these materials is low, the increased operating frequency was used to increase the resistance of the material to help heat it to the same degree as the ferromagnetic materials. 


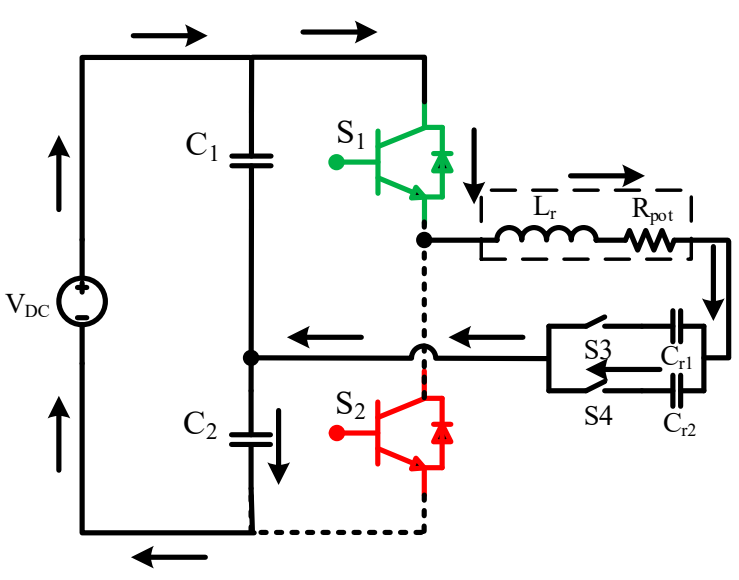

(a)

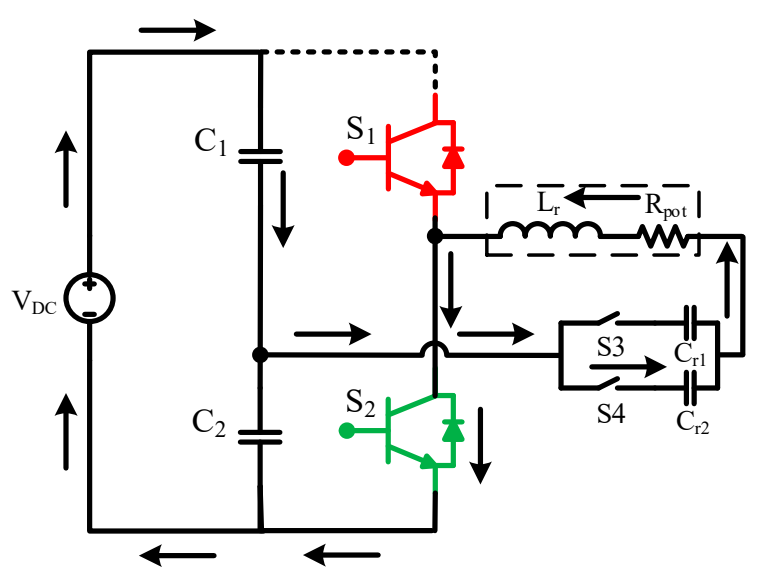

(b)

Figure 7. Circuit diagrams for non-ferrous heating mode: (a) S1 in ON state; (b) S2 in ON state.

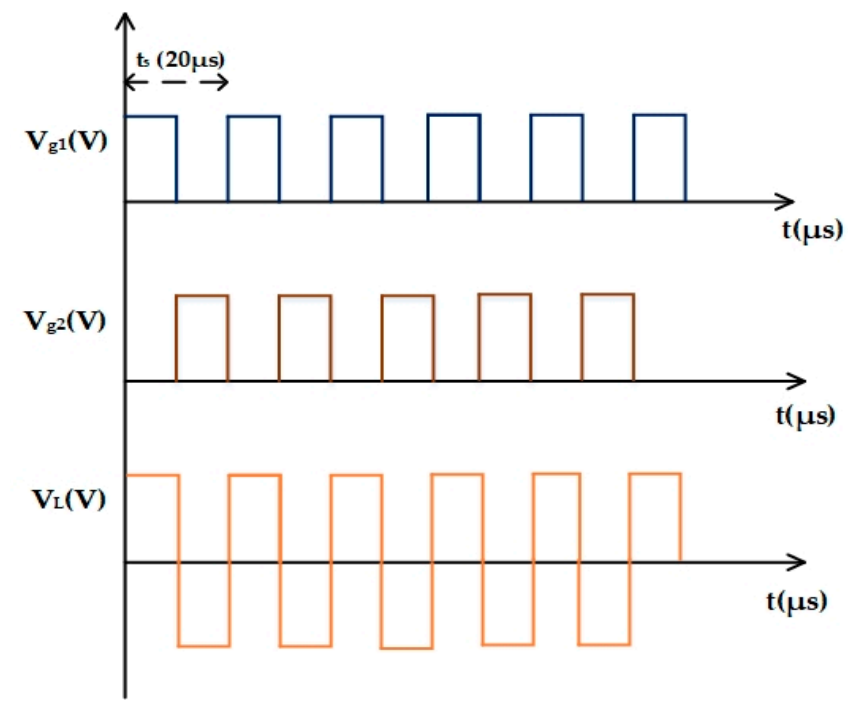

Figure 8. Pulses and load voltage waveforms for non-ferrous heating mode.

\subsection{Selection of the Operational Mode}

This study was designed for the heating of various metals of different sizes with the help of different operational modes. The mode selection algorithm was controlled with the help of circuit breakers and allows heating of the metals in the desired mode, as shown in Figure 9.

For each mode of operation, a separate circuit breaker was implemented in the hardware system; to change the mode of operation, a specific circuit breaker was closed, and the remaining breaker was open at that particular instant. Thus, for a particular mode, a specific circuit breaker was allotted. Thus, the breaker S3 was used to operate the system in ferrous heating mode, and S4 was used for non-ferrous heating mode. Firstly, when the metallic pot was placed in the IH system, voltage and current could be measured, and then, the pot resistance was calculated by using the expression mentioned in Figure 9. After that, the pot resistance at switching frequency was compared with the calculated pot resistance. If the condition was satisfied, then the switch S3 would be turned ON and ferrous heating mode would be selected; otherwise, it would move to the next condition. Here, the pot resistance at twice the switching frequency was compared with the calculated pot resistance; if it was satisfied, the $\mathrm{S} 4$ would be turned ON. However, if the condition was not satisfied, the system would stop. Under each mode of operation, specific values of resonant tank capacitor and inductor were connected to the system, and the breakers were used to isolate the unwanted part of the system, which was not required during each mode 
of operation. The values of the resonant capacitors and resonant inductors for each mode of operation are shown in Table 1.

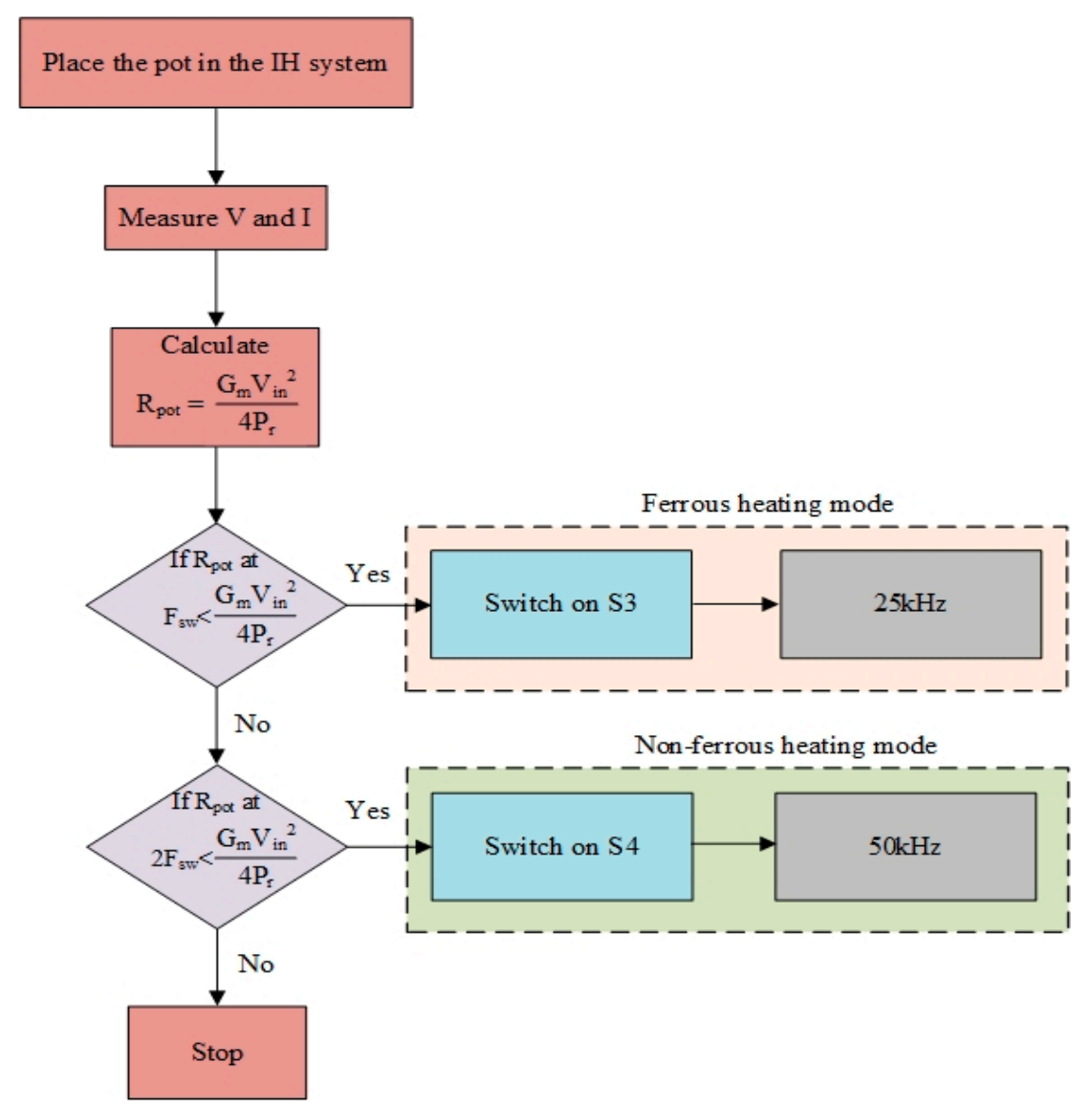

Figure 9. Flowchart for operational mode selection.

Table 1. Circuit parameters for different modes of operation.

\begin{tabular}{ccc}
\hline Parameters & Ferrous Heating Mode & Non-Ferrous Heating Mode \\
\hline$V_{\text {in }}($ Volts) & 220 & 220 \\
Capacitance $(\mathrm{C} 1)(\mathrm{mF})$ & 1.0 & 1.0 \\
Capacitance $(\mathrm{C} 2)(\mathrm{mF})$ & 1.0 & 1.0 \\
Pot resistance $(\mathrm{ohms})$ & 15.2 & 9.8 \\
Inductance $(\mathrm{Lr})(\mathrm{uH})$ & 160 & 160 \\
Capacitance $(\mathrm{Cr})(\mathrm{nF})$ & 253 & 63.3 \\
Resonant frequency $(\mathrm{kHz})$ & 25 & 50 \\
\hline
\end{tabular}

To design the hardware of the system, first, the rated power of the system was decided; after that, available input voltage was set to keep the current in the circuit minimum. Therefore, as per the proposed design, a $2 \mathrm{~kW}$ system with $220 \mathrm{~V}$ input voltage was used to test and verify the system's functionality. Theoretically, from the power $(P)$ formula (Equation (8)), the rated current $(I)$ of the system with an approximate value of $18 \mathrm{amps}$ could be obtained. Therefore, to be on the safe side, $20 \mathrm{~A}$ was taken as the rated current in hardware.

$$
P=V \times I
$$

As there is an electrical separation between the working coil and the workpiece in an $\mathrm{IH}$ system, the energy is transferred via magnetic coupling. The electrical counterpart of the IH load can be described as a transformer with a short-circuited secondary winding 
because it resembles transformer operation with the secondary circuits [23]. Figure 10 depicts the electrical equivalent model of the IH load.

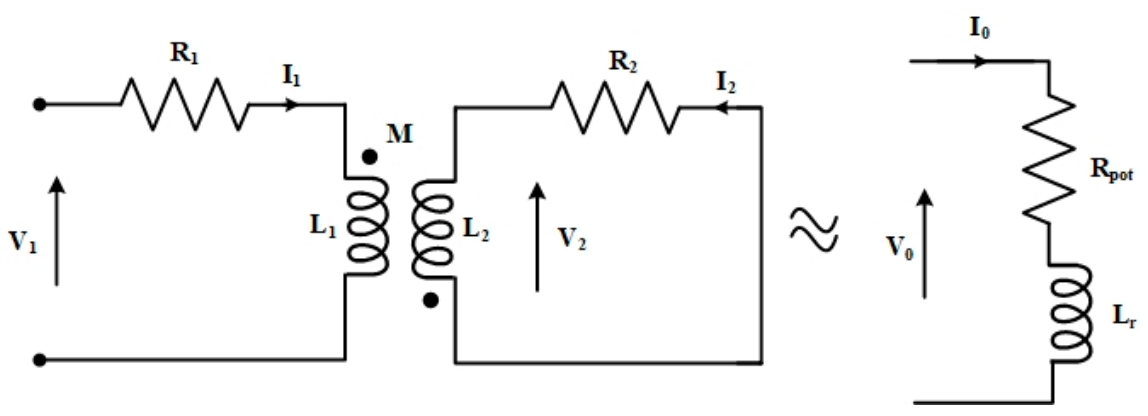

Figure 10. IH system's electrical equivalent load model.

By applying KVL to the above equivalent circuit, the resultant (Equations (9) and (10)) is as follows:

$$
\begin{gathered}
V_{1}=\left(j \omega_{s} L_{1}+R_{1}\right) I_{1}-j M \omega_{s} I_{2} \\
0=-j \omega_{s} I_{1} M+\left(R_{2}+j \omega_{s} L_{2}\right) I_{2} \\
\omega_{s}=2 \Pi F_{s}
\end{gathered}
$$

where current $I_{2}$ is given by Equation (12).

$$
I_{2}=\frac{j \omega_{s} I_{1} M}{R_{2}+j \omega_{s} L_{2}}
$$

By substituting Equation (13) in Equation (10), the expression can be defined by Equation (13).

$$
V_{1}=\left(j \omega_{s} L_{1}+R_{1}\right) I_{1}-j M \omega_{s}\left(\frac{j \omega_{s} I_{1} M}{R_{2}+j \omega_{s} L_{2}}\right)
$$

The preceding equation can be simplified into real and imaginary parts and equate the real part as $R_{\text {pot }}$ (Equation (14)) and the imaginary part as $L_{r}$ (Equation (15)).

$$
\begin{gathered}
R_{p o t}=R_{1}+\frac{M^{2} \omega_{s}^{2} R_{2}}{R_{2}^{2}+\omega_{s}^{2} L_{2}^{2}} \\
L_{r}=L_{1}+\frac{M^{2} \omega_{s}^{2} L_{2}}{R_{2}^{2}+\omega_{s}^{2} L_{2}^{2}}
\end{gathered}
$$

The mutual inductance can be expressed as Equation (16).

$$
M^{2}=\frac{\left(R_{p o t}-R_{1}\right)\left(R_{2}^{2}+\omega_{s}^{2} L_{2}^{2}\right)}{\omega_{S}^{2} R_{2}}
$$

The equations were used to calculate the equivalent resistance and inductance ( $R_{\text {pot }}$ and $\left.L_{r}\right)$, and the determined values were used in the simulation.

For the corresponding resonant frequency values, the resonant tank capacitor was calculated by Equation (17).

$$
C_{r}=\frac{1}{4 \pi^{2} F_{S}^{2} L_{r}}
$$

\section{Results and Discussion}

In this section, the hardware implementation and results of the proposed study, followed by the simulation results of two operating modes, are discussed. 


\subsection{Simulation Results of Heating Different Metals}

MATLAB software was used to obtain simulation results that used operating conditions similar to the experimental conditions. The simulation results of $2 \mathrm{~kW}$ power conversions according to different modes for different sizes of different metals are shown here. The input voltage and operating frequency variation according to the operating modes were also determined.

\subsubsection{Analysis of Results with Ferrous Heating Mode}

The operational waveform of the ferrous heating mode is shown in Figure 11. Switches S1 and S2 had complementary switching operations. The working frequency and the switching frequency both were the same. The $L_{r}$ and $C_{r}$ values selected for this mode were $160 \mathrm{uH}$ and $253 \mathrm{nF}$, respectively. From Figure 12, it could be inferred that the equivalent input voltage $(220 \mathrm{~V})$ in ferrous heating mode was twice the input voltage $( \pm 110 \mathrm{~V})$. The magnitude of the output voltage was nearly half of the input voltage. Therefore, the series resonant inverter transmitted the power of $1 \mathrm{~kW}$ in the resonant frequency of $25 \mathrm{kHz}$.

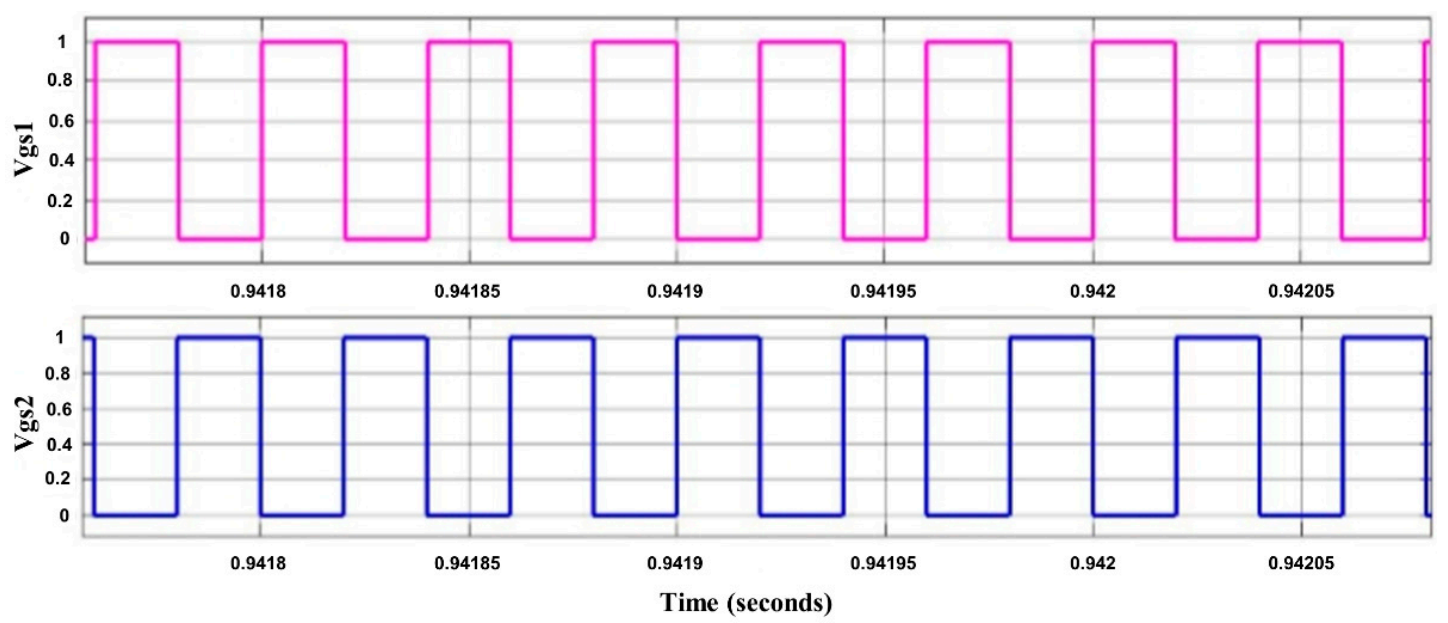

Figure 11. Switching waveforms for ferrous heating mode during simulation.
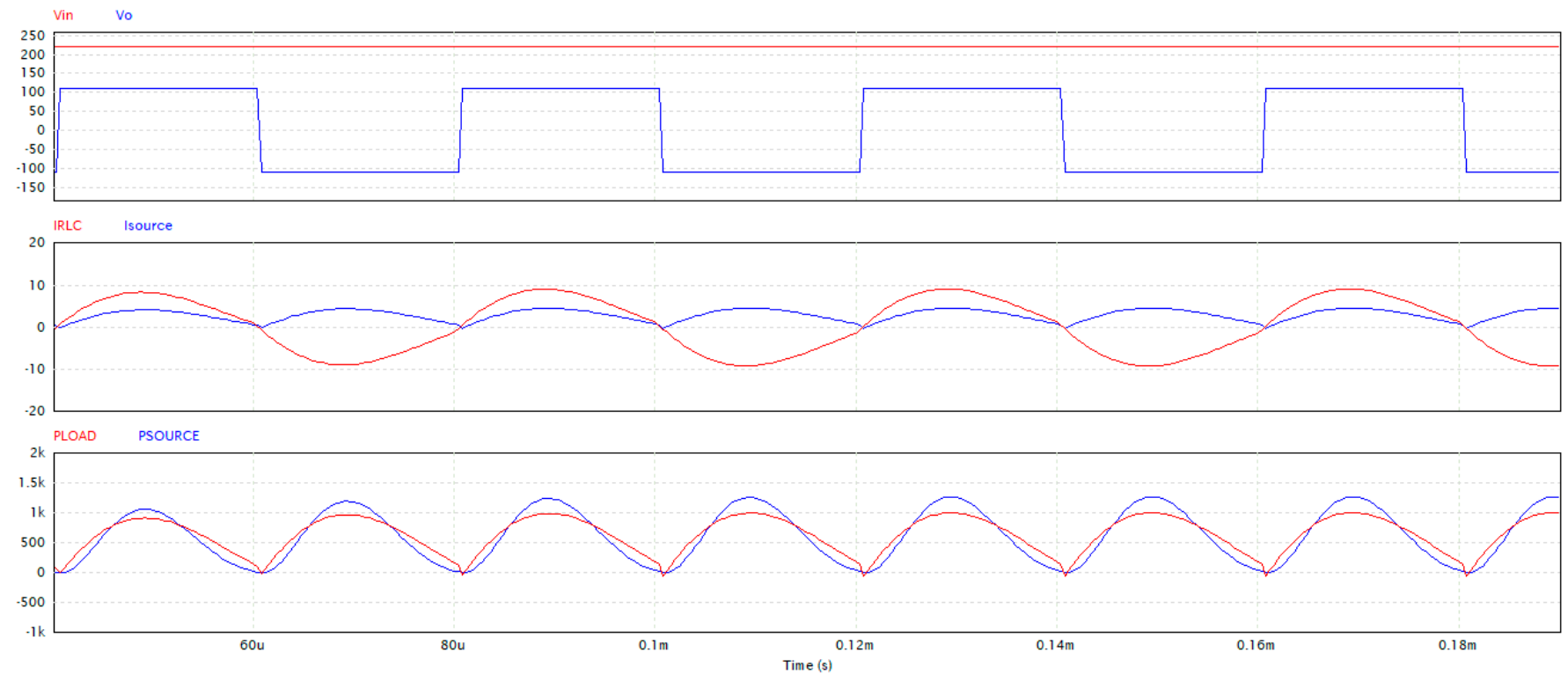

Figure 12. Power and voltage waveforms (input and output) for ferrous heating mode during simulation. 


\subsubsection{Analysis of Results with Non-Ferrous Heating Mode}

The non-ferrous heating mode could achieve twice the working frequency $(50 \mathrm{kHz})$ than the other mode switching frequency $(25 \mathrm{kHz})$. Here, switches S1 and S2 were turned on and off alternatively at double the frequency, which is shown in Figure 13.
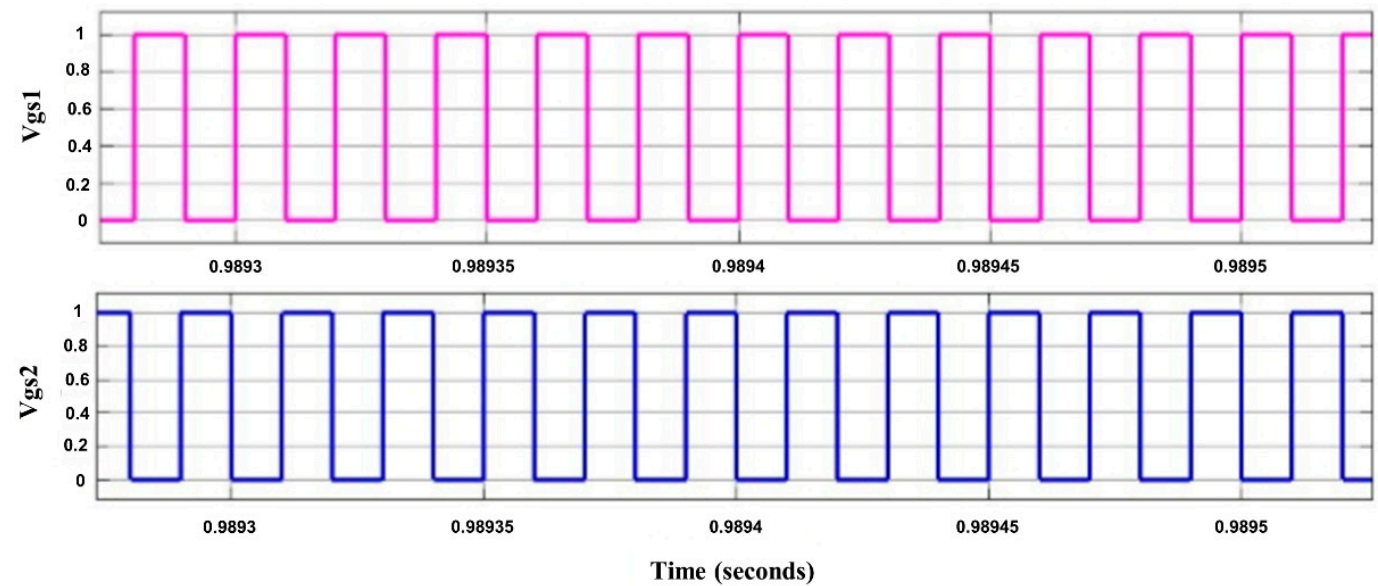

Figure 13. Switching waveforms for non-ferrous heating mode during simulation.

From Figure 14, it can be proved that the magnitude of the output voltage $( \pm 110 \mathrm{~V})$ was half of the input voltage $(220 \mathrm{~V})$. The output current of this mode was $14 \mathrm{~A}$, which was higher than that of the ferrous heating mode.
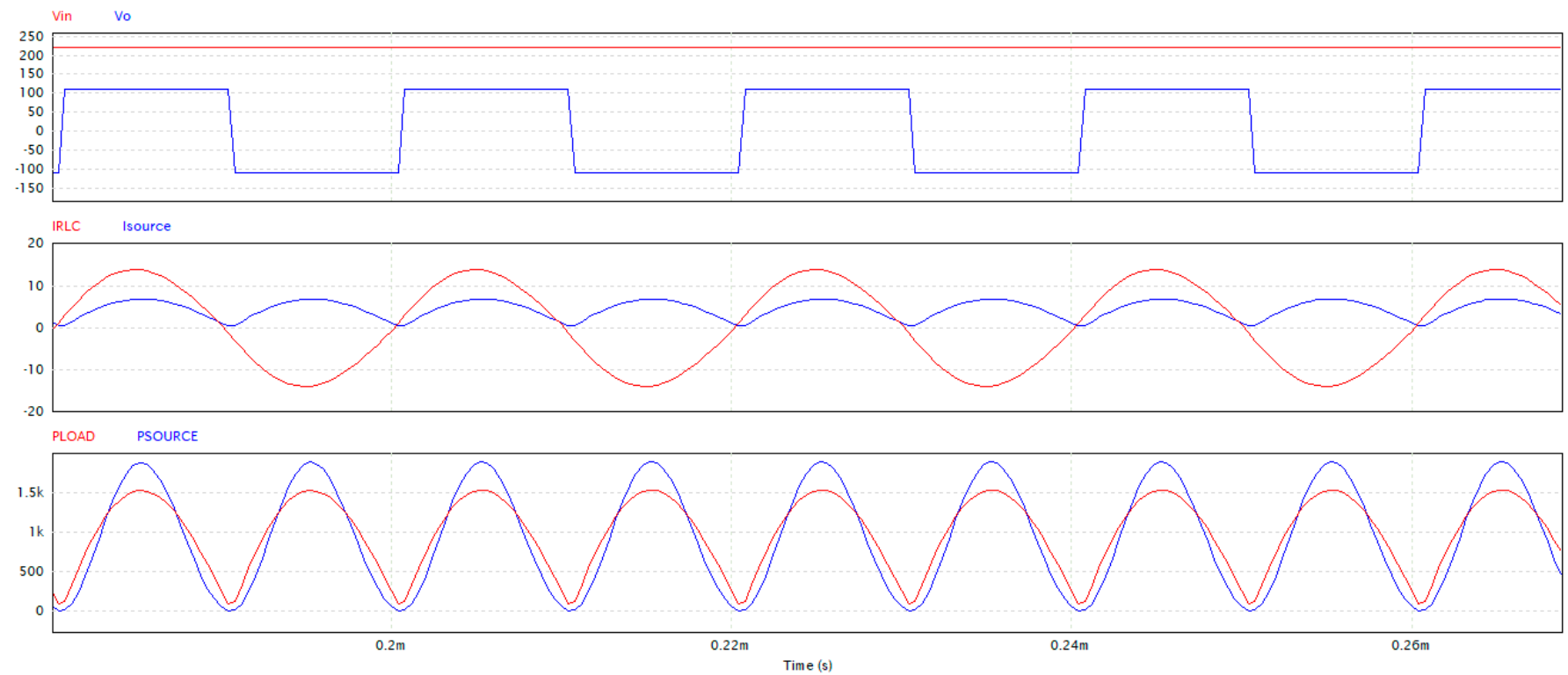

Figure 14. Power and voltage waveforms (input and output) for non-ferrous heating mode during simulation.

\subsection{Experimental Results of Heating Different Metals}

\subsubsection{Hardware Implementation}

Figure 15 shows the complete hardware integration setup of the $2 \mathrm{~kW}$ induction heating system that was tested at all different modes of operation and for different types and sizes of metals. In ferrous heating mode, stainless steel with the shape of a bowl and size of $8 \mathrm{~cm} \times 3.7 \mathrm{~cm}$ was used. On the other hand, for the non-ferrous heating mode, copper with the shape of a bowl and size of $8 \mathrm{~cm} \times 3.7 \mathrm{~cm}$ and aluminium with the shape of a bowl and size of $16 \mathrm{~cm} \times 3.2 \mathrm{~cm}$ were used. Figure 16 shows the working coils used for 
heating different shapes of metals. The first one was used to heat rod-type metals, whereas the second one was used to heat flattened surface vessels.

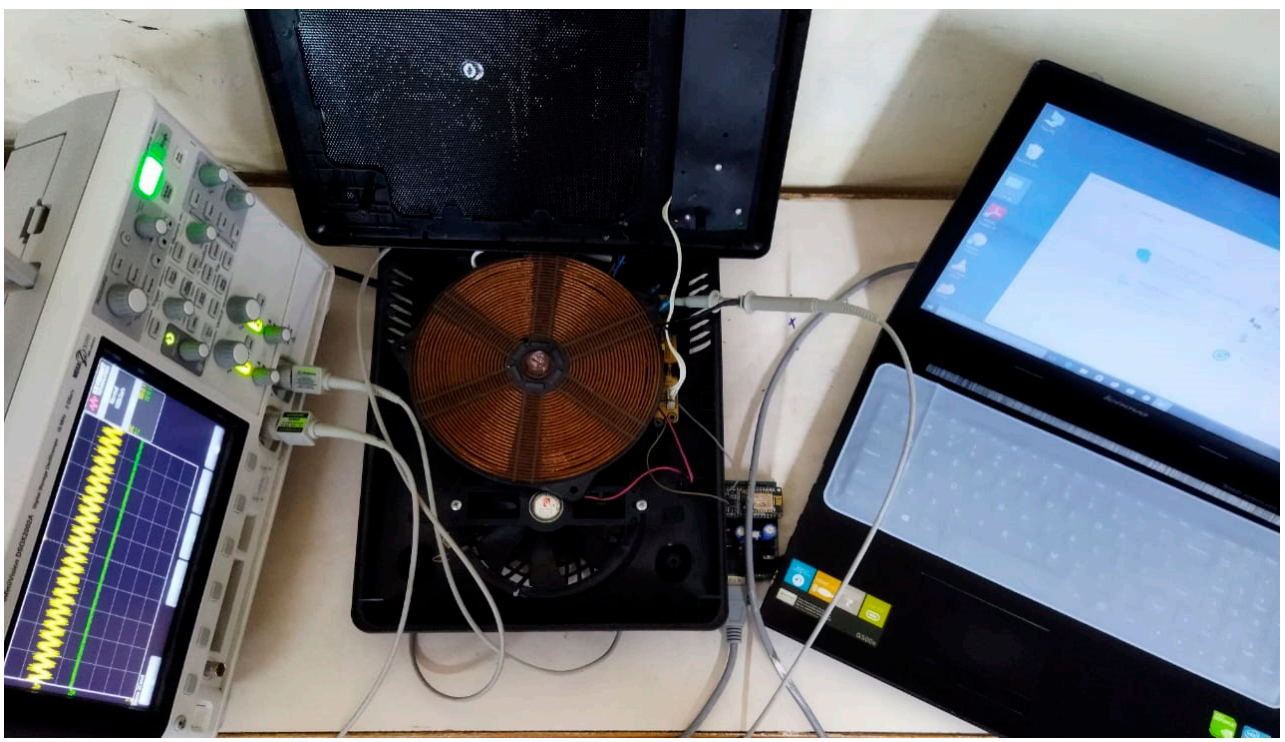

Figure 15. Experimental set-up of $2 \mathrm{~kW}$ induction heating system.

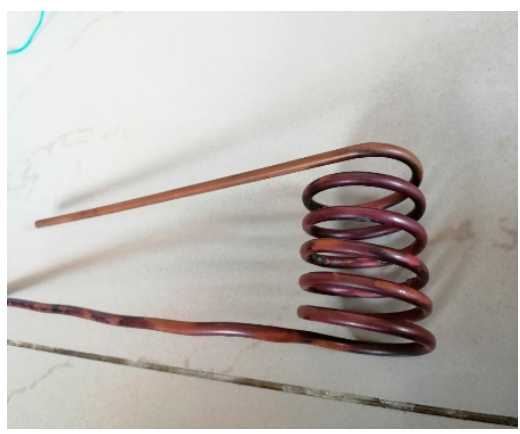

(a)

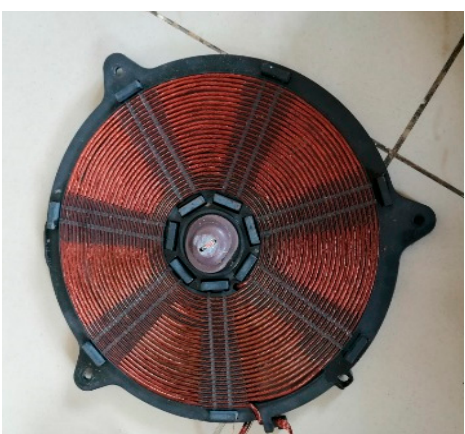

(b)

Figure 16. Working coils for (a) heating rods (b) heating flat vessels.

Heating metals of different types and different sizes is one of the complex barriers that the proposed system overcomes. Metals such as aluminium, copper, stainless steel, and iron of different sizes can be heated using different operating modes proposed. Since non-ferromagnetic materials have very low resistance, in order to heat them, the resistance of the materials should be increased. In order to increase the resistance, switching, as well as the resonant frequency, needs to be increased, which results in the heating of low-resistance metals. Table 2 shows different metals of different sizes and cross-sectional areas and the temperature to which they were heated in the proposed system. The temperature was measured using Fluke Ti401 at the central area of the object from a distance of approximately $40 \mathrm{~cm}$ with five repetitions for each set measurement. The thermal images for heating different metals are shown in Figure 17, in which the temperature distribution in different metals can be seen. The output waveforms were measured using a digital storage oscilloscope (Keysight InfiniiVision DSOX2002A). 
Table 2. Performance characteristics of metals in different heating modes.

\begin{tabular}{|c|c|c|c|c|}
\hline Type of Metal & Dimension (cm) & Weight (gm) & $\begin{array}{c}\text { Calculated } \\
\text { Temperature, } \mathrm{T}\left({ }^{\circ} \mathrm{C}\right)\end{array}$ & $\begin{array}{l}\text { Time Taken to Attain } \\
\text { Calculated Temperature (s) }\end{array}$ \\
\hline \multicolumn{5}{|l|}{ ALUMINIUM } \\
\hline Aluminium bowl & $\begin{aligned} \text { Diameter } & =16 \\
\text { Thickness } & =3.2\end{aligned}$ & 155 & $367^{\circ} \mathrm{C}$ & 656 \\
\hline $\begin{array}{l}\text { Aluminium rod } \\
\text { COPPER }\end{array}$ & $\begin{array}{l}\text { Diameter }=2.6 \\
\text { Length }=3.2\end{array}$ & 47 & $369^{\circ} \mathrm{C}$ & 700 \\
\hline Copper bowl & $\begin{array}{c}\text { Diameter }=8 \\
\text { Thickness }=3.7\end{array}$ & 166 & $377^{\circ} \mathrm{C}$ & 965 \\
\hline Copper round bar & $\begin{array}{c}\text { Diameter }=1.16 \\
\text { Length }=3.7\end{array}$ & 35.1 & $401{ }^{\circ} \mathrm{C}$ & 1000 \\
\hline \multicolumn{5}{|l|}{ STAINLESS STEEL (S4) } \\
\hline Stainless steel bowl & $\begin{array}{c}\text { Diameter }=8 \\
\text { Thickness }=3.7\end{array}$ & 144 & $889^{\circ} \mathrm{C}$ & 333 \\
\hline Stainless steel round bar & $\begin{array}{l}\text { Diameter }=1.72 \\
\text { Length }=3.7\end{array}$ & 68 & $906^{\circ} \mathrm{C}$ & 591 \\
\hline \multicolumn{5}{|l|}{ CAST IRON } \\
\hline Iron pan & $\begin{aligned} \text { Diameter } & =16 \\
\text { Thickness } & =3.2\end{aligned}$ & 152 & $315^{\circ} \mathrm{C}$ & 765 \\
\hline Iron rod & $\begin{array}{c}\text { Diameter }=1.7 \\
\text { Length }=3.2\end{array}$ & 53 & $400{ }^{\circ} \mathrm{C}$ & 768 \\
\hline
\end{tabular}

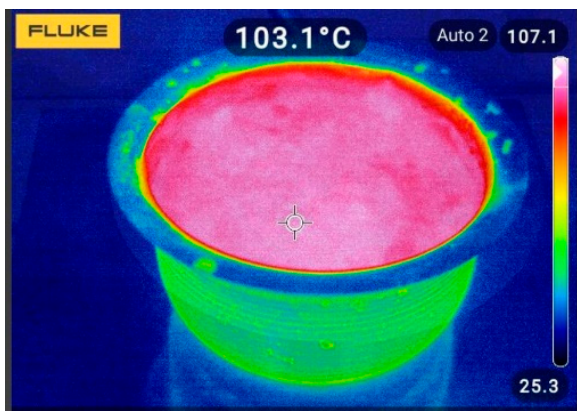

(a)

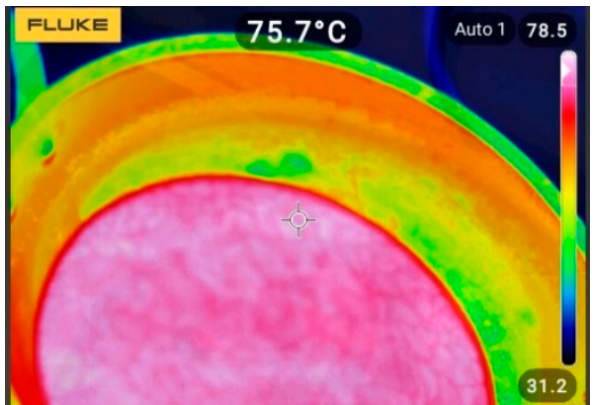

(b)

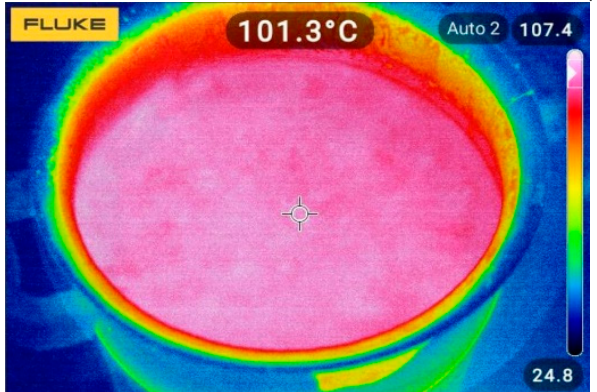

(c)

Figure 17. Thermal image of heating different metals: (a) stainless steel; (b) aluminium; (c) copper (power rating: $2 \mathrm{~kW}$ and time period: $100 \mathrm{~s}$ ).

\subsubsection{Practical Results of Ferrous Heating Mode}

Figure 18 presents the experimental results of ferrous heating mode operation, wherein the output voltage was $+108.9 \mathrm{~V}$ to $-108.9 \mathrm{~V}$, and the output current was approximately 8.59 A. In this mode, as the ferrous metals have high resistance, a resonant frequency of $25 \mathrm{kHz}$ was applied to heat the ferrous metals. The switching frequency applied for this mode was nearly $25 \mathrm{kHz}$. 


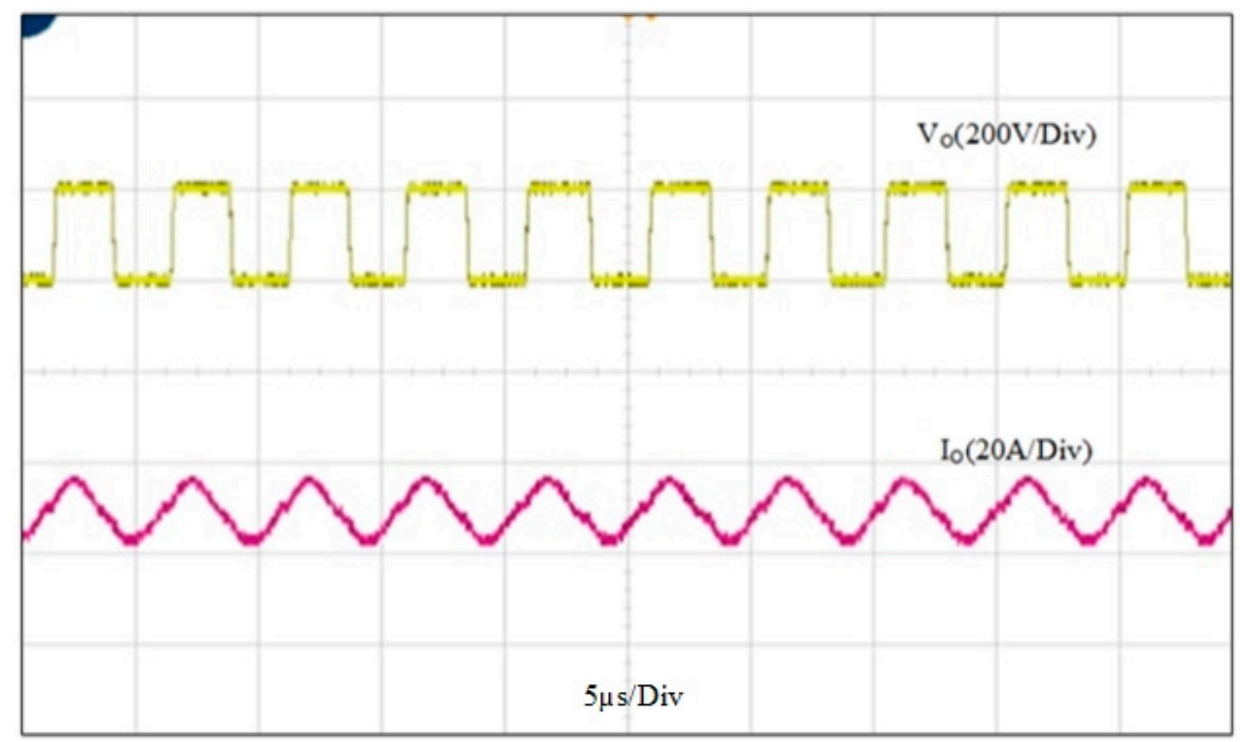

Figure 18. Output waveforms for ferrous heating mode during experiment.

\subsubsection{Practical Results of Non-Ferrous Heating Mode}

As presented in Figure 19, the experimental results of non-ferrous heating mode operation indicate that the output voltage was nearly $+108.3 \mathrm{~V}$ to $-108.3 \mathrm{~V}$, and the output current was approximately 13.2 A. The resonant and switching frequency applied for this mode was $50 \mathrm{kHz}$. Here, a two-times higher operating frequency could increase the pot resistance, which resulted in the vessel becoming heated. This mode had higher output current when compared with the ferrous heating mode due to low resistance.

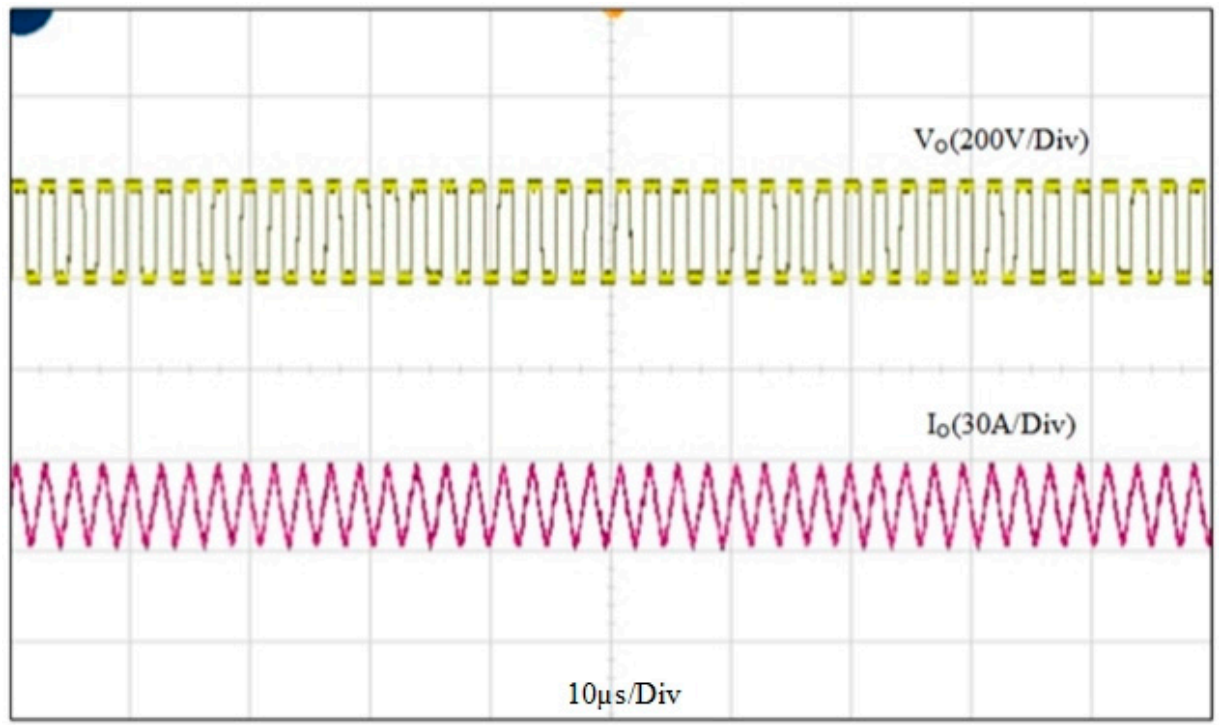

Figure 19. Output waveforms for non-ferrous heating mode during experiment.

\subsection{General Discussion}

From the simulation and experimental results, it was concluded that in ferrous heating mode, regardless of the voltage given as the input, half of that voltage magnitude was obtained on the output side. For example, if $220 \mathrm{~V}$ was provided in the input side, in simulation, $\pm 110 \mathrm{~V}$ was obtained, while in the experiment, $\pm 108.9 \mathrm{~V}$ was obtained as the output, which means the magnitude of the output voltage was half of that of the input voltage on both positive and negative sides. Likewise, in non-ferrous heating mode, the output voltage was nearly half of the input voltage. For example, if $220 \mathrm{~V}$ was given as the input, the simulation output was nearly $\pm 110 \mathrm{~V}$, and the experimental output was 
around \pm 108.3 V. Furthermore, the experimental results demonstrate that the proposed method successfully heated several types of pots. The comparison of the results between the simulation and experiment is shown in Table 3. The results clearly demonstrate that the system worked equally efficiently both in ferrous and non-ferrous heating modes.

Table 3. Comparison between simulation and experimental results.

\begin{tabular}{|c|c|c|c|c|c|c|c|}
\hline \multirow{2}{*}{$\begin{array}{l}\text { Types of } \\
\text { Metal }\end{array}$} & \multirow{2}{*}{$\begin{array}{c}\text { Switching } \\
\text { Frequency } \\
\quad(\mathbf{k H z})\end{array}$} & \multicolumn{3}{|c|}{ Simulation Results } & \multicolumn{3}{|c|}{ Experimental Results } \\
\hline & & $\begin{array}{c}\text { Output Voltage, } \\
\text { Vo (V) }\end{array}$ & $\begin{array}{c}\text { Output Current, } \\
\text { Io (A) }\end{array}$ & $\begin{array}{c}\text { Output Power, } \\
\text { Po (W) }\end{array}$ & $\begin{array}{c}\text { Output Voltage, } \\
\text { Vo (V) }\end{array}$ & $\begin{array}{l}\text { Output Current, } \\
\text { Io (A) }\end{array}$ & $\begin{array}{c}\text { Output Power, } \\
\text { Po (W) }\end{array}$ \\
\hline Ferrous & 25 & $\pm 110 \mathrm{~V}$ & $9 \mathrm{~A}$ & 990 & $\pm 108.9 \mathrm{~V}$ & $8.59 \mathrm{~A}$ & 935.5 \\
\hline Non-ferrous & 50 & $\pm 110 \mathrm{~V}$ & $14 \mathrm{~A}$ & 1540 & $\pm 108.3 \mathrm{~V}$ & $13.2 \mathrm{~A}$ & 1429.6 \\
\hline
\end{tabular}

This proposed FLM method may have some limitations such as noise and vibration for lightweight vessels due to resonance. It can be used to heat other non-ferrous metals and can also be implemented in a system with a power higher or lower than $2 \mathrm{~kW}$. Park and Jung [12] proposed a system for heating different metals, whereas in this research, different shapes, as well as different metals, were used for heating; moreover, in the previous study, the series resonance inverter was powered by using the AC source, followed by the rectifier, whereas in this study, the AC source was replaced by DC source, so the rectification stage was eliminated, resulting in the reduction in the size of the circuit and the cost. While the authors of the previous study selected aluminium and stainless steel for their work, here, we used four different metals-aluminium, copper, stainless steel, and iron. A half-bridge series resonant inverter with a modified version was proposed for heating ferromagnetic and non-ferromagnetic pans [11], which operated in two operating modes such as first-harmonic and third-harmonic operating modes, and when compared with [12], it had reduced circuit components but still consisted of a rectifier. The herein proposed structure was an optimal one that catered to two important traits of induction heating system-namely, variable load and variable size. At the outset, the overall structure (Figure 3) seemed to be a complex one since the microgrid had been represented with many sources. Induction heating was one such entity applied in a microgrid, and therefore, the IH structure was not a complex one. Additionally, another added advantage of the proposed scheme was the single-stage inversion as the rectification stage was discarded. This made the proposed IH structure sufficiently simple. The various methods used in the literature for variable-load induction heating systems, compared with the current system, are shown in Table 4. The major advantages of this proposed system are cost effectiveness, wide heating capability, lower power consumption, improved power density, etc.

Table 4. Comparison of different variable-load induction heating systems.

\begin{tabular}{|c|c|c|c|}
\hline Study & Key Technology & Scheme Topology & Remarks \\
\hline Millan et al. [11] & Selective harmonic scheme & $\begin{array}{l}\text { Modified half-bridge series } \\
\text { resonant inverter. }\end{array}$ & $\begin{array}{c}\text { The authors proposed a modified topology } \\
\text { of half-bridge inverter with two operation } \\
\text { modes of selective harmonics. }\end{array}$ \\
\hline Park and Jung [12] & $\begin{array}{l}\text { Load adaptive modulation } \\
\text { (LAM) }\end{array}$ & Full bridge series resonant converter. & $\begin{array}{l}\text { LAM was proposed by the authors to vary } \\
\text { the input voltage magnitude of IH coil and } \\
\text { series resonant inverter's operating } \\
\text { frequency based on the pot resistance. }\end{array}$ \\
\hline Tanaka [15] & - & Half-bridge series resonant inverter. & $\begin{array}{l}\text { Examined the input resistance of different } \\
\text { metals and determined the finest condition } \\
\text { for a high-frequency inverter. }\end{array}$ \\
\hline Shoji et al. [20] & - & Buck-boostfull-bridge inverter. & $\begin{array}{l}\text { The authors applied this method for } \\
\text { induction cookers with left and right sides to } \\
\text { heat all metals. }\end{array}$ \\
\hline Proposed system & Flexible load modulation (FLM) & Half-bridge resonant converter & $\begin{array}{l}\text { Here, FLM was proposed to heat various } \\
\text { loads with variable sizes by using a } \\
\text { half-bridge resonant converter without any } \\
\text { rectification stage. }\end{array}$ \\
\hline
\end{tabular}




\section{Conclusions}

In this proposed research, the use of flexible load modulation (FLM) was implemented to achieve heating of a wide range on both ferromagnetic and non-ferromagnetic materials. The modes of operation depend upon the workpiece such that for ferrous-type materials, the switching frequency was $25 \mathrm{kHz}$, and it was $50 \mathrm{kHz}$ for the non-ferrous materials. The frequency variation achieved through this flexible load modulation was simulated and realized as a hardware prototype for a $2 \mathrm{~kW}$ system. The results demonstrated that the suggested scheme was very effective for variable shapes and sizes in both ferrous and non-ferrous materials. The effectiveness of heating with respect to the time duration for different workpieces was investigated and duly captured through a thermal camera. The research proposed here can be extended by imparting an artificial intelligence system for improving the system response.

Author Contributions: Conceptualisation, S.R.R., C.S.B. and S.R.; methodology, S.R.R., C.S.B., S.R., M.A. and J.H.; software, S.R.R., C.S.B. and S.R.; validation, S.R.R., C.S.B., S.R., M.A. and J.H..; formal analysis, S.R.R., C.S.B., S.R., M.A. and J.H.; investigation, S.R.R., C.S.B. and S.R.; resources, C.S.B. and S.R.; data curation, S.R.R., C.S.B. and S.R.; writing-original draft preparation, S.R.R., C.S.B. and S.R.; writing - review and editing, S.R.R., C.S.B., S.R., M.A. and J.H.; visualisation, C.S.B., S.R., M.A. and J.H.; supervision, C.S.B., S.R., M.A. and J.H.; project administration, C.S.B. and S.R. All authors have read and agreed to the submitted version of the manuscript.

Funding: This research received no external funding.

Institutional Review Board Statement: Not applicable.

Informed Consent Statement: Not applicable.

Data Availability Statement: The data presented in this study are available in the article.

Acknowledgments: The authors would like to thank the team of Manchester Met University for their all kinds of support for this research and for preparing the manuscript.

Conflicts of Interest: The authors declare no conflict of interest.

$\begin{array}{ll}\text { Nomenclature } \\ V_{D C} & \text { Input DC voltage for the system } \\ L_{r} & \text { Resonant tank inductor } \\ C_{r} & \text { Resonant tank capacitor } \\ t_{s} & \text { Time period of PWM pulses } \\ G_{m} & \text { Maximum voltage gain } \\ P_{f} & \text { Maximum power in ferrous heating mode } \\ P_{n f} & \text { Maximum power in non-ferrous heating mode } \\ \text { FLM } & \text { Flexible load modulation } \\ \text { IH } & \text { Induction heating } \\ R_{p o t} & \text { Resistance of the material to be heated } \\ F_{S} & \text { Resonance frequency } \\ F_{s w} & \text { Switching frequency } \\ \text { PWM } & \text { Pulse width modulation } \\ P_{r} & \text { Rated power }\end{array}$

\section{References}

1. Lucía, Ó.; Maussion, P.; Dede, E.J.; Burdío, J.M. Induction heating technology and its applications: Past developments current technology and future challenges. IEEE Trans. Ind. Electron. 2014, 61, 2509-2520. [CrossRef]

2. Acero, J.; Burdio, J.M.; Barragan, L.A.; Navarro, D.; Alonso, R.; Ramon, J.; Monterde, F.; Hernandez, P.; Lorente, S.; Garde, I. Domestic induction appliances: An overview of recent research. In Proceedings of the 2008 Twenty-Third Annual IEEE Applied Power Electronics Conference and Exposition, Austin, TX, USA, 24-28 February2008; pp. 39-47.

3. Sarnago, H.; Lucia, O.; Burdio, J.M. A Versatile Resonant Tank Identification Methodology for Induction Heating Systems. IEEE Trans. Power Electron. 2018, 33, 1897-1901. [CrossRef] 
4. Baldan, M.; Stolte, M.-H.; Nacke, B.; Nurnberger, F. Improving the Accuracy of FE Simulations of Induction Tempering Toward a Microstructure-Dependent Electromagnetic Model. IEEE Trans. Magn. 2020, 56, 1-9. [CrossRef]

5. Sackl, S.; Zuber, M.; Clemens, H.; Primig, S. Induction Tempering vs Conventional Tempering of a Heat-Treatable Steel. Metall. Mater. Trans. A 2016, 47, 3694-3702. [CrossRef]

6. Watanabe, T.; Nagaya, S.; Hirano, N.; Fukui, S.; Furuse, M. Development of Conduction-Cooled Superconducting Split Coil for Metal Melting by DC Induction Heating. IEEE Trans. Appl. Supercond. 2018, 28, 1-4. [CrossRef]

7. Han, W.; Chau, K.T.; Liu, W.; Tian, X.; Wang, H. A Dual-Resonant Topology-Reconfigurable Inverter for All-Metal Induction Heating. IEEE J. Emerg. Sel. Top. Power Electron. 2021, 1. [CrossRef]

8. Park, S.M.; Jang, E.; Joo, D.; Lee, B.K. Power curve-fitting control method with temperature compensation and fast-response for all-metal domestic induction heating systems. Energies 2019, 12, 2915. [CrossRef]

9. Llorente, S.; Monterde, F.; Burdío, J.M.; Acero, J. A Comparative Study of Resonant Inverter Topologies Used in Induction Cookers. In Proceedings of the Applied Power Electronics Conference (APEC), Dallas, TX, USA, 10-14 March 2002; Volume 2, pp. $1168-1174$.

10. Lucia, O.; Burdio, J.M.; Millan, I.; Acero, J.; Puyal, D. Load-adaptive control algorithm of half-bridge series resonant inverter for domestic induction heating. IEEE Trans. Ind. Electron. 2009, 56, 3106-3116. [CrossRef]

11. Millán, I.; Burdío, J.M.; Acero, J.; Lucía, O.; Llorente, S. Series resonant inverter with selective harmonic operation applied to all-metal domestic induction heating. IET Power Electron. 2011, 4, 587-592. [CrossRef]

12. Park, H.-P.; Jung, J.-H. Load-adaptive modulation of a series-resonant inverter for all-metal induction heating applications. IEEE Trans. Ind. Electron. 2018, 65, 6983-6993. [CrossRef]

13. Han, W.; Chau, K.T.; Zhang, Z. Flexible induction heating using magnetic resonant coupling. IEEE Trans. Ind. Electron. 2017, 64, 1982-1992. [CrossRef]

14. Han, W.; Chau, K.T.; Zhang, Z.; Jiang, C. Single-source multiple-coil homogeneous induction heating. IEEE Trans. Magn. 2017, 53, $1-6$.

15. Tanaka, T. A new induction cooking range for heating any kind of metal vessels. IEEE Trans. Consum. Electron. 1989, 35, 635-641. [CrossRef]

16. Koertzen, H.W.; van Wyk, J.D.; Ferreira, J.A. Design of the Non-ferrous high resistance heating mode series resonant converters for induction cooking. In Proceedings of the Power ElectronicsSpecialistConference Records, Atlanta, GA, USA, 18-22 June 1995; pp. 729-735.

17. Acero, J.; Lope, I.; Carretero, C.; Burdio, J.M. Adapting of non-metallic cookware for induction heating technology via thin-layer nonmagnetic conductive coatings. IEEE Access 2020, 8, 11219-11227. [CrossRef]

18. Oncu, S.; Unal, K.; Tuncer, U. Laboratory setup for teaching resonant converters and induction heating. Eng. Sci. Technol. 2021, in press. [CrossRef]

19. Dawson, F.P.; Jain, P. A comparison of load commutated inverter Systems for Induction Heating and Melting Applications. IEEE Trans. Power Electronics 1991, 6, 430-441. [CrossRef]

20. Shoji, H.; Uruno, J.; Isogai, M.; Yanagidaira, T. Buck-Boost-Full-Bridge Inverter for All-Metals Induction Heating Cookers. IEEJ J. Ind. Appl. 2016, 5, 339-346. [CrossRef]

21. Ahmed, N.A.; Nakaoka, M. Boost-half-bridge edge resonant soft switching PWM high-frequency inverter for consumer induction heating appliances. IEEE Proc. Electr. Power Appl. 2006, 153, 932-938. [CrossRef]

22. Sadakata, H.; Fujita, A.; Saha, B.; Ahmed, T.; Nakaokaet, M. Latest practical developments of triplex series load resonant frequency operated high frequency inverter for induction-heated low resistivity metallic appliances in consumer built-in cooktops. In Proceedings of the 2010 Twenty-Fifth Annual IEEE Applied Power Electronics Conference and Exposition (APEC 2010), Palm Springs, CA, USA, 21-25 February2010; pp. 1825-1832.

23. Vishnuram, P.; Ramachandiran, G.; Ramasamy, S.; Dayalan, S. A comprehensive overview of power converter topologies for induction heating applications. Int. Trans. Electr. Energ. Syst. 2020, 30, e12554. [CrossRef]

24. Sarnago, H.; Lucía, O.; Burdio, J.M. Multiresonant power converter for improved dual-frequency induction heating. IEEE Trans. Power Electron. 2019, 34, 2097-2103. [CrossRef]

25. Fernández, M.; Perpiñà, X.; Rebollo, J.; Velllvehi, M.; Sánchez, D.; Cabeza, T.; Lorente, S.; Jordà, X. Solid-state relay solutions for induction cooking applications based on advanced power semiconductor devices. IEEE Trans. Ind. Electron. 2019, 66, 1832-1841. [CrossRef]

26. Gomes, R.C.M.; Vitorino, M.A.; Acevedo-Bueno, D.A.; de RossiterCorrêa, M.B. Multiphase resonant inverter with coupled coils for AC-AC induction heating application. IEEE Trans. Ind. Appl. 2020, 56, 551-560. [CrossRef]

27. Komeda, S.; Fujita, H. A phase-shift-controlled direct AC-to-AC converter for induction heaters. IEEE Trans. Power Electron. 2018, 33, 4115-4124. [CrossRef]

28. Sarnago, H.; Guillén, P.; Burdío, J.M.; Lucia, O. Multiple-output ZVS resonant inverter architecture for flexible induction heating appliances. IEEE Access 2019, 7, 157046. [CrossRef]

29. Saha, B.; Kim, R. High Power Density Series Resonant Inverter Using an Auxiliary Switched Capacitor Cell for Induction Heating Applications. IEEE Trans. Power Electron. 2014, 29, 1909-1918. [CrossRef]

30. Vishnuram, P.; Ramachandiran, G. Capacitor-less induction heating system with self-resonant bifilar coil. Int. J. Circ. Theory Appl. 2020, 48, 1411-1425. [CrossRef] 
31. Rudnev, V.; Loveless, D.; Cook, R.L. Handbook of Induction Heating; CRC Press: Boca Raton, FL, USA, 2017. [CrossRef]

32. Bleiker, S. Fabrication of Through Silicon Vias (TSVs)with RF Capability by Magnetic Assembly of Nickel Wires. Master's Thesis, KTH Royal Institute of Technology, Stockholm, Sweden, 2011. 